\title{
Luis Miguel Glave. La república instalada. Formación nacional y prensa en el Cuzco, 1825-1839
}

Isabelle Tauzin Castellanos

\section{(2) OpenEdition}

\section{Journals}

Edición electrónica

URL: http://journals.openedition.org/bifea/5672

DOI: $10.4000 /$ bifea. 5672

ISSN: 2076-5827

\section{Editor}

Institut Français d'Études Andines

Edición impresa

Fecha de publicación: 1 mayo 2005

Paginación: 127-129

ISSN: 0303-7495

\section{Referencia electrónica}

Isabelle Tauzin Castellanos, « Luis Miguel Glave. La república instalada. Formación nacional y prensa en el Cuzco, 1825-1839 », Bulletin de l'Institut français d'études andines [En línea], 34 (1) | 2005, Publicado el 08 abril 2005, consultado el 04 diciembre 2020. URL : http://journals.openedition.org/bifea/5672 ; DOI : https://doi.org/10.4000/bifea.5672

\section{(c) 980}

Les contenus du Bulletin de l'Institut français d'études andines sont mis à disposition selon les termes de la licence Creative Commons Attribution - Pas d'Utilisation Commerciale - Pas de Modification 4.0 International. 


\section{Reseñas}

Luis Miguel GLAVE - La república instalada. Formación nacional y prensa en el CuzCo, 1825-1839. Instituto de Estudios Peruanos. Lima, 2004, 251 p.

La república instalada. Formación nacional y prensa en el Cuzco, 1825-1839 nos ofrece un ensayo de historia cultural sobre los tumultuosos años 1825-1839, tiempo en que la figura del cuzqueño Agustín Gamarra ocupó el centro del escenario político nacional. Luis Miguel Glave refunde aquí la segunda parte de su tesis doctoral presentada en Sevilla y dedicada al proceso de formación de la identidad peruana a partir de una fuente de difícil acceso, cuando no desaparecida: la prensa regional. De esa forma Glave organiza un diálogo entre historia cultural, historia de la vida cotidiana e historia política.

Como lo recuerda el autor, los especialistas de la historia del libro y de la lectura han mostrado que el analfabetismo no impidió el acceso a las letras gracias a la práctica de la lectura oral; un solo lector informaba a decenas de oyentes. La cultura popular incluso infiltró la cultura letrada de tal manera que los periódicos constituyen una fuente heterogénea, de manejo arriesgado que junta lo verdadero y lo falso, la realidad y el chisme, las normas y los comunicados. Además, según Glave, la enseñanza de la lectura dada con fines de dominación tuvo consecuencias impensadas como la escritura autodidacta aprendida con fines domésticos.

La exactitud científica resulta una meta aún más difícil de alcanzar cuando se trabaja con representaciones colectivas y con documentación incompleta, como suelen serlo las colecciones de periódicos. Por eso mismo es loable el esfuerzo de este ensayo al dar una imagen a la vez global y detallada del Cuzco desgarrado entre la tentación del orden y la inminencia de la sedición. El autor rememora investigaciones hechas en México y Bolivia acerca de las sociedades rurales que han recurrido a múltiples formas y materiales (textiles, canciones, representaciones teatrales...) para informar y expresar su visión de la realidad histórica.

La ley de libertad de imprenta consecutiva a las luchas emancipadoras en la península tuvo efectos imprevisibles en América con el auge del periodismo reglamentario e ideológico. El modelo de la prensa doctrinal fue El investigador, un periódico liberal moderado que brindaba noticias locales como la llegada de barcos a Lima y proporcionaba información política discutida en los cafés, el espacio ilustrado reservado a la élite mientras que las clases populares se reunían en las pulperías. Glave refiere que para captar un público más amplio, el poder político llegó a traducir al quechua la proclama que anunció en 1812 
la constitución española y el advenimiento de la era liberal. Lo que buscaba entonces la Corona era mantener el imperio y detener el proceso emancipador. La competencia entre sueltos impresos e información periodística era tanto más fuerte que en un soporte idéntico se vendían oraciones destinadas a fomentar la religiosidad.

Glave trae a la memoria la versatilidad política demostrada por las figuras de la aristocracia y algunos editores como Gaspar Rico apresado en tiempos del virrey Abascal por difundir El Peruano y que acabó sosteniendo a La Serna con El depositario.

La finalidad de los periódicos era doble: difundir las luces y prescribir una norma de conducta colectiva a lo largo y lo ancho del territorio nacional emergente. Suscribirse al periódico oficial constituía un acto patriota muy recomendado para las autoridades deseosas de mantenerse con el cambio de régimen. El oportunismo político no sólo se dio en Lima sino también en el Cuzco. La antigua capital del imperio inca se benefició de la imprenta oficial del virrey trasladada en los últimos momentos de la Colonia. E, ironía del destino, tal presencia iba a favorecer el surgimiento de una «vanguardia del periodismo» con el gobierno de Agustín Gamarra.

«La república instalada» es el título del segundo capítulo y centro del libro: proporciona un panorama de la variopinta prensa sureña. El Sol del Cuzco es el semanal más representativo por su longevidad (1825-1829) y la personalidad de su redactor, Carlos Gallegos en quien Glave ve al periodista por antonomasia. Gamarra llega para asumir la gobernación de la ciudad con el flamante título de prefecto. El Sol publica nombres de patriotas excelsos y cuestiona la integración de antiguos funcionarios de alto rango. Tal postura independiente origina el primer incidente a causa del apoyo brindado por Gamarra a uno de sus antiguos condiscípulos. Además de periodista, Gallegos era doctor en teología; en público lo acusa un conspicuo miembro de la Iglesia cuzqueña por alentar grupos anticlericales y cuestionar el celibato de los curas.

El debate religioso trasciende las páginas de El Censor Eclesiástico dirigido por Benito Laso. Laso pone en tela de juicio los privilegios políticos y económicos de la Iglesia y reivindica la participación peruana en el proceso de la independencia integrando a la figura de Túpac Amaru. Con la intromisión de Gamarra en el país vecino, Laso es vilipendiado por El Eco de La Paz; también sufre persecuciones en Arequipa por sus críticas anticlericales. Al reconstruir la instalación de la república, Glave hace revivir a los prohombres de la Indepencia como Laso o Vidaurre, cuyas vidas fueron contradictorias y no tan lineales como las ha rememorado la historiografía oficial. El investigador se enfrenta a la variabilidad de las circunstancias y tiene que superar la dificultad de cómo identificar articulistas anónimos y destacar textos valiosos inmersos entre sueltos triviales que advierten contra la presencia de forasteros o la plaga de perros, expresiones de la vida callejera desvinculada de la alta política.

En 1829 llega una nueva imprenta al Cuzco mejorando la difusión de la información con la creación de La Minerva que sustituye a El Sol. Editada por el gaditano Francisco de Miranda, La Minerva elogia al presidente Gamarra y defiende los intereses del prefecto Bujanda. Da cuenta de la historia local, haciendo hincapié en algunos temas como la educación o la visita al Cuzco de un jefe hanakmbut en 1830. Con eso, Glave evidencia la falsedad etnocéntrica de las noticias alarmistas acerca de los ataques de «salvajes» a lo largo del siglo XIX. La vida cotidiana también se vislumbra en El Triunfo de la Libertad (1830-1831) que informa sobre la construcción de un panteón, las funciones teatrales, la instalación de una fábrica textil.

En el Cuzco de aquellos años se llega a dar más relevancia al cumpleaños de Agustín Gamarra que a la celebración de la victoria de Ayacucho. La disputa por el poder local nace de pretextos nimios entre allegados de Gamarra y Santa Cruz; los defectos del Perú contemporáneo ya apuntan en el personalismo de los caudillos militares a expensas de la 
población indígena cuya contribución financia los puestos públicos en constante aumento. Glave comprueba una verdadera «proliferación impresa» de panfletos hacia 1835; El CuzCo Libre reemplaza La Minerva y un nuevo prefecto se beneficia del apoyo de El Regulador de la Opinión. Poco tiempo después sale El Fiera-brás que recurre al ingenio y a las burlas más soeces en contra de Salaverry. Se enfrentan asimismo mediante sueltos y libros dos libertadores, O'Brien y Miller, instalados en el Cuzco en busca de nuevas riquezas en la selva o en las minas de la Colonia.

Después de aquellos años de sedición vuelve la calma con la Confederación PerúBoliviana festejada con corridas de toros y circos de equitación a los que anuncian avisos en los periódicos. A partir de abril de 1836, La Estrella Federal — con ese nombre que los cuzqueños bien pueden leer como metáfora halagüeña de su ciudad — difunde las nuevas normativas del estado sud-peruano. Se organiza la vida pública de manera ejemplar: la policía, los pasaportes, la moneda, los gremios de artesanos, los teatros, el ornato y limpieza son objetos de reglamentos cuyo respeto corre a cargo del propio cuñado del presidente Santa Cruz, el prefecto Larrea, interesado también en exportar sus producciones de textiles y aguardientes hacia Bolivia. En medio de la pacificación y bonanza, Ilama la atención la emergencia de una revista dedicada a la cultura: de modo independiente, gracias a la iniciativa ejemplar de José Palacios, sale El Museo Erudito (1837-1839). Con traducciones del francés y del inglés, textos de historia, geografía o literatura, Palacios proporciona a sus conciudadanos nuevos conocimientos sobre el Perú y el mundo: así es como el Ollantay está incluido en la revista en 1837.

Ahora bien, a pesar de los beneficios aportados por la Confederación, crece de forma soterrada la hostilidad a los bolivianos. El resentimiento chauvinista estalla en enero de 1839 con una asonada en la que los cuzqueños manifiestan su temor a un traslado del Señor de los Temblores al país vecino. Se dan escenas de gran violencia referidas sin tapujos por las cartas de los testigos, a diferencia de la versión oficial de los periódicos que reducen el motín a unos vagos percances. Consecuencia del suceso será el regreso triunfal de Gamarra al Cuzco en mayo de 1839; lo festejará una nueva publicación: La Libertad Restaurada. El fragor de la asonada sólo quedará en la historia gracias a la versión novelada de Narciso Aréstegui en El padre Horán (1848).

Otros periódicos efímeros son evocados con acierto por Glave: La Brújula, Cocachos, El Atalaya integran la dimensión joco-seria y dan paso a regionalismos y quechuismos imposibles de leer en la prensa de Lima. La agitación del Cuzco en los primeros decenios de la Independencia renace gracias al estudio de la prensa, sugiriendo nuevas posibilidades de conocer las vidas y costumbres de un vasto Perú ignorado a lo largo del XIX por la élite limeña para quien simple y llanamente la Sierra no existía. 